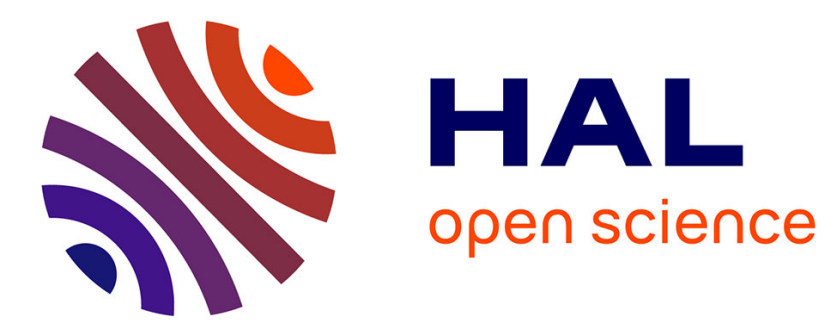

\title{
Can federal grants mitigate social competition?
}

Jacques H. Dreze, Charles C. Figuieres, Jean Hindriks

\section{To cite this version:}

Jacques H. Dreze, Charles C. Figuieres, Jean Hindriks. Can federal grants mitigate social competition?. CESifo Economic Studies, 2007, 53 (4), pp.596-617. 10.1093/cesifo/ifm020 . hal-02660016

\section{HAL Id: hal-02660016 https://hal.inrae.fr/hal-02660016}

Submitted on 30 May 2020

HAL is a multi-disciplinary open access archive for the deposit and dissemination of scientific research documents, whether they are published or not. The documents may come from teaching and research institutions in France or abroad, or from public or private research centers.
L'archive ouverte pluridisciplinaire HAL, est destinée au dépôt et à la diffusion de documents scientifiques de niveau recherche, publiés ou non, émanant des établissements d'enseignement et de recherche français ou étrangers, des laboratoires publics ou privés. 


\title{
Can Federal Grants Mitigate Social Competition?
}

\author{
Jacques H. Drèze*, Charles Figuieres ${ }^{\dagger}$ and Jean Hindriks ${ }^{\ddagger}$
}

17 September 2007

\begin{abstract}
The European economic integration leads to increasing mobility of factors, thereby threatening the stability of social transfer programs. This paper investigates the possibility to achieve by means of voluntary matching grants both the optimal allocation of factors and the optimal level of redistribution in the presence of factor mobility. We use a fiscal competition model a la Wildasin (1991) in which states differ in their technologies and preferences for redistribution. We first investigate a simple process in which the federal authority progressively raises the matching grants to the district choosing the lowest transfer and all districts respond optimally to the resulting change in transfers all around. This process is shown to increase efficiency of both production and redistribution. However it does not guarantee that all districts gain, nor that an efficient level of redistribution is attained. Assuming complete information among districts, we derive the willingness of each district to match the contribution of other districts and we show that the aggregate willingness to pay for matching rates converges to zero when both the efficient level of redistribution and the efficient allocation of factors are achieved. We then describe an adjustment process for the matching rates that will lead districts to the efficient outcome and guarantee that everyone will gain.

Keywords: Fiscal Federalism, Adjustment Process, Matching Grants, Social Competition.
\end{abstract}

JEL Classification: $\mathrm{H} 23, \mathrm{H} 70$

${ }^{*}$ CORE, Voie du Roman Pays 34, B-1348 Louvain-la-Neuve, Belgium.

${ }^{\dagger}$ INRA, UMR LAMETA. 2 place Viala. 34060 Montpellier cedex 01. France.

${ }^{\ddagger}$ CORE, Department of Economics, Universite catholique de Louvain.

${ }^{0}$ This paper is based on keynote lecture at the IFIR and CESIfo conference on "New Directions in Fiscal Federalism" held in Lexington, Kentucky (14-16 September 2006). We thank our discussant Massimo Bordignon, conference participants, two referees and the Editors David Wildasin and Thiess Buettner for valuable comments. 


\section{Introduction}

The problem we address in this paper is the income protection of workers in a market that is increasingly integrated. In Europe, wage subsidies have been advocated for low-skilled workers and partly implemented in some countries (France, Belgium, the Netherlands) in the form of reduced rates of employers' contributions to social security at low wages. The additional employment due to the wage subsidies in France is estimated by Crépon and Deplatz (2002) at 470.000 persons; that is about $3 \%$ of total employment in the private sector.

A related question is the income protection of the non-working poor. We do not address this issue directly in the paper because we believe it requires specific training and employment policies that differ from the Federal grants we advocate in this paper. Therefore our contribution on income protection of workers should be viewed as complementary to the set of contributions on employment protection and creation. Note also that the recent tendency in welfare reforms in many developed countries, including European states, makes unemployment benefits conditional to some form of activity ${ }^{1}$. This trend obviously blurs the distinction between the working and non-working poor.

With the recent enlargement of the European Union, we need to address the income protection of workers in a context where there are no legal barriers to migration so that a migration externality is at work. According to Hans-Werner Sinn (1990): "Any country that tries to establish an insurance state would be driven to bankruptcy because it would face emigration of the lucky who are suppose to give and immigration of the unlucky who are supposed to receive."

This prediction of a "race to the bottom" is too extreme; ${ }^{2}$ it rests on limited theoretical and empirical support. This is probably due to the presence of significant costs and barriers to migration. ${ }^{3}$ (Welfare shopping has

\footnotetext{
The paper is an extension of earlier versions presented at the TAPES conference of the NBER and CESIfo on "fiscal federalism" held in Munich (20-22 May 2004). Thanks are due to our two discussants there Alex Plekhanov and Jacob L. Vigdor. We also thank seminar participants at Bern, Bonn, Cologne, and Toulouse for comments and suggestions.

${ }^{1}$ It takes the strongest form, called workfare, when social assistance is contingent upon participation in mandatory work measures (as in USA, Canada, and UK) and a softer form, called welfare-to-work, when it calls upon voluntary participation from the recipients (as in France, Germany). See Lodemel and Trickey (2000).

${ }^{2}$ See, e.g., Bertola et al. (2001).

${ }^{3}$ See Belot and Ederveen (2006).
} 
been discouraged in Europe by limiting portability across member states and subjecting eligibility to previous employment in the country). However we believe that underprovision of income protection in an integrated labour market is an issue that cannot be ignored in the EU. Even if it has not been a pressing issue to date, fiscal competition on both capital and labour markets is already there. And with the enlargement, this issue will become more pressing, as extensively discussed in Wildasin (2000).

The objective of this paper is to clarify the role of the EU in the provision of income protection to workers in the context of market integration. Our proposal is EU co-financing of national programs through a system of matching grants, with special attention to implementation. ${ }^{4}$ The key questions are: could a programme of matching grants, possibly at differentiated rates, be adopted unanimously? Could it be so defined that all member states gain regardless of their differences? Could it be implemented voluntarily by member states (henceforth "districts") instead of being imposed by a perfectly informed and powerful central planner as suggested in the existing literature (see Wildasin, 1991).

The motivation is enhanced efficiency rather than redistribution across districts. The existing literature does not quite answer these questions: it only provides an existence result for efficient matching rates, assuming (implicitly) that the net gains could be redistributed in a lump sum fashion so that everyone benefits, and that there exists a central authority endowed with all the relevant information to implement the efficient solution. The more interesting question is whether the efficient policy could emerge from a negotiation process which simultaneously guarantees that an efficient outcome is reached and that every member state gains.

To clarify the issues, we start with a simple model proposed by Wildasin (1991) in his seminal paper "Income Redistribution in a Common Labour Market". That model does not predict a race to the bottom but only too little redistribution to the workers and an inefficient allocation of workers across districts. Also, Wildasin (1991) shows that when labor is mobile and each district seeks to redistribute income to workers through transfers it is possible to achieve the efficient allocation of labour and at the same time the optimal level of redistribution by means of differentiated matching grants. Districts with lower preference for redistribution should face higher matching grants so as to equate transfer levels and achieve the efficient allocation of

\footnotetext{
${ }^{4}$ This proposal was first developed by Jacques H. Drèze (2002) in a Tinbergen Lecture, where he writes:"...I look at the problem of income protection for disadvantaged workers as a problem of ex-ante insurance"; see Drèze (2000) for an elaboration of this theme. The word "redistribution" hereafter is used as a shortcut.
} 
labour across districts.

The main problem with this analysis is that local preferences for redistribution are not observable to the federal authority; even worse, the federal authority required to operate these matching grants may not exist or may not have the power to implement them. In fact if such discretionary power existed, the federal authority possessing all the relevant information could directly implement the optimal solution by imposing a uniform transfer in all districts. But this solution is hardly feasible in the European context where redistribution policies are a competence of the state (i.e., subsidiarity principle). The purpose of this paper is to investigate the possibility of voluntary matching grants among districts based on reciprocal matching; more precisely, we investigate whether there exists some adjustment process based on each district's decisions that can bring about the optimal matching rates. $^{5}$

It should be emphasized that our solution requires the participants to be informed about the technology and tastes of the other participants. This is because voluntary matching of the other participants' contributions requires to know how they would respond to such matching. This is, of course, more restrictive than one would like. Therefore as a complement to this process, we propose another process that does not require complete information to implement the optimal matching rates. The central idea is that the regulatory authority can correct an inefficient Nash equilibrium by raising the matching rate of the district choosing the lowest transfer. This will induce all other states to adjust their transfer levels. These adjustments all around will increase total production and the level of redistribution. This process is budget-balanced but it does not guarantee that every district will gain, nor that an efficient level of redistribution is attained.

We use the same model as Wildasin (1991) modulo the fact that districts take into account that they will have to pay their share of the additional cost of matching grants. In Wildasin, the presumption is that there are enough districts for each to ignore the effects of its policy on its contribution to the financing of matching grants. We develop our analysis in a general setting of heterogenous districts that differ both with respect to their preferences and to their technologies. ${ }^{6}$

\footnotetext{
${ }^{5}$ Another interesting approach that does not require the existence of a strong central authority is the immigration controls as suggested in Wilson (2006). But this solution conflicts with the EU policy which seeks precisely to remove all the barriers to migration.

${ }^{6}$ The problem we address is related to, but more general than, the voluntary matching models of Guttman (1978) or Varian (1994) who deal with pure public goods. These authors propose a simple multistage mechanism and use the refinement of subgame per-
} 
The paper is organized as follows. Section 2 presents the framework. Pareto optimal allocations are characterized in Section 3. Section 4 proposes a simple process implementing efficient matching grants without assuming complete information among districts. Section 5 studies the willingness of districts to match contributions of other districts under complete information. Section 6 uses these findings to investigate a dynamic adjustment process of matching rates that converges to the efficient solution, with the property that every district is made better-off along the process. Section 7 concludes.

\section{The framework}

A federation is composed of $n \geq 2$ districts indexed by $i$. In each district there is a large group of immobile residents; there are also $l_{i}$ workers that are mobile. Let $L$ denote the the total number of mobile workers in the economy. Thus

$$
\sum_{i} l_{i}=L
$$

Each district produces a private consumption good with a specific $\mathrm{Ri}$ cardian technology $f_{i}\left(l_{i}\right)$, which is increasing and concave $\left(f_{i}^{\prime}\left(l_{i}\right)>0\right.$ and $\left.f_{i}^{\prime \prime}\left(l_{i}\right)<0\right)$. Workers are paid their marginal product: wage in district $i$ is $w_{i}\left(l_{i}\right)=f_{i}^{\prime}\left(l_{i}\right)$ which is decreasing in the number of workers in that district: $\left(w_{i}^{\prime}\left(l_{i}\right)=f_{i}^{\prime \prime}\left(l_{i}\right)<0\right)$.

The per capita transfer that accrues to the workers in district $i$ is denoted $z_{i}$. The total income of a worker in district $i$ is thus $w\left(l_{i}\right)+z_{i} \cdot{ }^{7}$ Workers can migrate at no cost from one district to another. Accordingly, for any vector of transfers $\mathbf{z}=\left(z_{1}, \ldots, z_{i}, \ldots, z_{n}\right)$ :

$$
w\left(l_{i}\right)+z_{i}=w\left(l_{j}\right)+z_{j} \equiv c(\mathbf{z}) \quad \forall j, i .
$$

This generates an allocation of labor $\mathbf{l}(\mathbf{z})=\left(l_{1}, \ldots, l_{i}, \ldots, l_{n}\right)$ across districts and a uniform income for the workers $c=c(\mathbf{z})$. The labour demand function in district $i$ is $l_{i}\left(w_{i}\right)=l_{i}\left(c-z_{i}\right)$ with $l_{i}^{\prime}\left(c-z_{i}\right)=f_{i}^{\prime \prime}\left(l_{i}\right)^{-1}<0$.

fection à la Moore-Repullo to implement an efficient outcome. In our model, each player will react optimally to the matching rates and those responses will determine all around the level of redistribution and the allocation of labor across districts.

${ }^{7}$ Note that if the firms were paying the transfer, they would equal marginal product of labor to the wage plus the transfer, $f_{i}^{\prime}\left(l_{i}\right)=w_{i}+z_{i}$. However this specification cannot capture the migration induced by transfers and moreover transfers will have offsetting effect on wages leaving total income unchanged. 
The migration effect of a change in $z_{i}$ at constant $z_{j}$ 's (for all $j \neq i$ ) is obtained by totally differentiating (1) and (2) with respect to $z_{i}, l_{i}, l_{j}$ which gives the system of equations:

$$
\begin{aligned}
\sum_{k} d l_{k} & =0, \\
\frac{1}{l_{i}^{\prime}} d l_{i}+d z_{i} & =d c, \\
\frac{1}{l_{j}^{\prime}} d l_{j} & =d c, \text { for } j \neq i .
\end{aligned}
$$

From (3) and (5):

$$
d l_{i}=-d c \sum_{j \neq i} l_{j}^{\prime}
$$

Using this equality in (4):

$$
\frac{1}{l_{i}^{\prime}}\left(-d c \sum_{j \neq i} l_{j}^{\prime}\right)+d z_{i}=d c,
$$

which yields as in Wildasin (1991) :

$$
\frac{d c}{d z_{i}}=\frac{l_{i}^{\prime}}{\sum_{j} l_{j}^{\prime}} \equiv \sigma_{i} \in(0,1)
$$

and the general-equilibrium effect of a change in the transfer level $z_{i}$ on the allocation of labour across districts is

$$
\begin{aligned}
& \frac{d l_{i}}{d z_{i}}=-\left(1-\sigma_{i}\right) l_{i}^{\prime}>0 \\
& \frac{d l_{j}}{d z_{i}}=\sigma_{i} l_{j}^{\prime}<0 .
\end{aligned}
$$

Each district $i$ receives the matching grant $s_{i} z_{i} l_{i}$ from the federation (with $\left.0 \leq s_{i} \leq 1\right)$ and contributes $\varphi_{i} \sum_{j} s_{j} z_{j} l_{j}$ to balance the federal budget, (with $0 \leq \varphi_{i} \leq 1$ and $\sum_{i} \varphi_{i}=1$ ). Both subsidy rates $s_{i}$ and contribution rates $\varphi_{i}$ are common knowledge. 
The immobile residents of each district capture the return to the fixed factors of production. Hence the net income of the immobile residents in district $i$ is

$$
\begin{aligned}
y_{i} & =f_{i}\left(l_{i}\right)-f_{i}^{\prime}\left(l_{i}\right) l_{i}-\left(1-s_{i}\right) z_{i} l_{i}-\varphi_{i} \sum_{j} s_{j} z_{j} l_{j}, \\
& =f_{i}\left(l_{i}\right)-f_{i}^{\prime}\left(l_{i}\right) l_{i}-\left(1-\left(1-\varphi_{i}\right) s_{i}\right) z_{i} l_{i}-\varphi_{i} \sum_{j \neq i} s_{j} z_{j} l_{j} .
\end{aligned}
$$

Following Widasin (19991), the social welfare in each district $i$ is an increasing function of the incomes of its immobile residents and its mobile workers, that we express as

$$
W^{i}\left(y_{i}, c\right)=y_{i}+U^{i}(c)
$$

It is assumed to be quasi-linear with partial derivatives $U_{c c}^{i}<0 \leq U_{c}^{i}$. Thus, $M R S^{i}=W_{2}^{i} / W_{1}^{i}=U_{c}^{i} \geq 0$ denotes district $i$ 's marginal willingness to redistribute income to workers. ${ }^{8}$ Quasi-linearity is assumed in order to obviate income effects in the subsequent analysis ${ }^{9}$. Note that the objective function is independent of the number of residents of either type. This assumption of exogenous social welfare is again more restrictive than what one would like. But with free migration, $l_{i}$ is endogenous to the policy choices and allowing for a welfare function that depends on the relative number of each group would make the analysis of the Nash equilibrium much more complex ${ }^{10}$. It is also fair to say that there is no agreement in social choice

\footnotetext{
${ }^{8}$ The unif coefficient for $y_{i}$ in the social welfare function means that $U^{i}(c)$ is evaluated in equivalent units of $y_{i}$. See footnote 12 below for aggregation over districts.

${ }^{9}$ With a large number of immobile residents, $y_{i}=\sum_{h} y_{i}^{h}$ and $d y_{i}=\sum_{h} d y_{i}^{h}$. If the preferences of $h$ in district $i$ are represented by $u^{h}\left(y_{i}^{h}\right)$ then $u^{h}\left(y_{i}^{h}+d y_{i}^{h}\right)-$ $u^{h}\left(y_{i}^{h}\right) \simeq \frac{\partial u^{h}}{\partial y_{i}^{h}}\left(d y_{i}^{h}-\frac{\left(d y_{i}^{h}\right)^{2}}{y_{i}^{h}} R_{R}^{h}\right)$, where $R_{R}^{h}$ is a coefficient of relative risk aversion. The quasi-linearity assumption amounts to ignoring the second-order terms proportional to $\left(d y_{i}^{h}\right)^{2} / y_{i}^{h}$.

${ }^{10}$ Roberts (1999) provides a first step in this direction by examining the process and outcomes of majority voting over public goods in a club whose preferences and policy choices relate to its membership; and in turn its policy choices determine its membership. See also Drèze and Greenberg (1980) for a cooperative game approach where players's preferences are directly related to the composition of the coalition to which they belong (i.e. hedonic coalitions). They showed that efficiency requires transfers across coalitions and stability requires penalties for leaving a coalition.
} 
theory about how to make social welfare evaluation with a variable population. In particular using the utilitarian criterion with a variable population leads to the so-called "repugnant" solution of an infinitely large population with infinitely low per capita utility (for a recent synthesis see Blackorby, Bossert and Donaldson, 2005).

Districts choose their transfer level taking as given the transfer levels of other districts, resulting in aNash equilibrium such that for each district $i$

$\frac{d W^{i}}{d z_{i}}=\left(U_{c}^{i}-l_{i}\right) \sigma_{i}+\left(1-\varphi_{i}\right) s_{i} l_{i}+\left(1-\left(1-\varphi_{i}\right) s_{i}\right)\left(1-\sigma_{i}\right) z_{i} l_{i}^{\prime}-\varphi_{i} \sum_{j \neq i} s_{j} z_{j} \frac{d l_{j}}{d z_{i}}=0$

where, by (6), $\sigma_{i}$ is the change in the net income $c$ of the workers resulting from an increase in $z_{i}$, and $-\left(1-\sigma_{i}\right) l_{i}^{\prime}$ is the change in the number of workers resulting from this increase in $z_{i}$.

\section{Pareto optimality}

In this model any Pareto optimal allocation solves

$\max _{l_{i}, y_{i}, c} \Lambda=\sum_{i} \lambda_{i}\left(y_{i}+U^{i}(c)\right)+\mu\left[\sum_{i} y_{i}+c \sum_{i} l_{i}-\sum_{i} f_{i}\left(l_{i}\right)\right]+v\left[\sum_{i} l_{i}-L\right]$

where $\lambda=\left(\lambda_{1}, \ldots, \lambda_{i}, \ldots, \lambda_{n}\right)$ is an arbitrary weighting system with $\lambda_{i}>0$ and $\sum_{i} \lambda_{i}=1$. The necessary first-order conditions are:

$$
\begin{gathered}
\frac{\partial \Lambda}{\partial l_{i}}=\mu\left(c-f_{i}^{\prime}\left(l_{i}\right)\right)+v=0, \\
\frac{\partial \Lambda}{\partial y_{i}}=\lambda_{i}+\mu=0, \\
\frac{\partial \Lambda}{\partial c}=\sum_{i} \lambda_{i} U_{c}^{i}+\mu \sum_{i} l_{i}=0=\mu \sum_{i}\left(U_{c}^{i}-l_{i}\right) .
\end{gathered}
$$


The condition $f_{i}^{\prime}\left(l_{i}\right)=c+\frac{v}{\mu}$ is the productive efficiency condition (equalization of the marginal productivity of labour across districts). The condition $\sum_{i}\left(U_{c}^{i}-l_{i}\right)=0$ may be interpreted as the Bowen-Lindahl-Samuelson condition for the efficient level of redistribution $c$ which is akin to a public good. $\sum_{i}\left(U_{c}^{i}-l_{i}\right)>0$ means underprovision and conversely ${ }^{11}$. Given $\lambda^{*}$, the Pareto optimal solution is denoted $l_{i}^{*}, y_{i}^{*}, c^{*}$.

Wildasin (1991) shows that without matching grants, the Nash equilibrium among districts will not be efficient due to the migration externality. Anticipating correctly the migration flows and taking the transfer levels of other districts as given, each district acting independently settles for a level of redistribution that is too low (as expected from voluntary contributions to a public good); also, wages are not equalized across districts resulting in inefficient allocation of labour. Wildasin (1991) proposes a solution involving the intervention of a Federal authority that can impose Pigovian corrections in the form of matching grants, and obtains first-order conditions characterising an optimum. Some caution is needed, because the characterisation relies on the first-order conditions of the districts which are non-linear so that the set of Nash equilibria $\mathbf{z}=\left(z_{1}, \ldots, z_{i}, \ldots, z_{n}\right)$ might not be convex. The consequence is that first-order conditions do not guarantee a global optimum, although such an optimum exists and is characterized by the production efficiency and redistribution efficiency. ${ }^{12}$ The non-convexity of the set of Nash equilibria is also relevant to our analysis, but not crippling because we are mostly interested by matching rates adjustments capable of achieving welfare improvement and benefitting to all participants. We then provide a simple ex-post check to verify if the dynamic adjustment process has reached a Pareto optimal allocation.

Wildasin's solution also leaves open the question of implementation. In particular how could such differentiated matching grants be designed, when the regulator does not have access to all the relevant information about technology and preferences required to implement the efficient outcome?

In implementation problems, specifying the exact nature of the information possessed and used by the agents, and therefore the relevant equilibrium concept apt to predict their behaviors is crucial, and our case is no exception. In Wildasin (1991), the informational structure underlying the Nash equilibrium of Section 2 remains unspecified; indeed it is not needed

\footnotetext{
${ }^{11}$ Note that the Bowen-Lindahl-Samuelson condition does not preclude contributions to differ from willingness-to-pay for some individuals $\frac{W_{2}^{i}}{W_{1}^{i}}-l_{i} \lessgtr 0$ provided that on average the differences cancel out.

${ }^{12}$ Wildasin (1991) makes the distinction between necessary and sufficient conditions.
} 
for the derivation of the Pigovian subsidies. But this aspect becomes a central matter in the present paper. Generally, there are two distinct informational assumptions underlying the Nash equilibria. In a first case, a Nash equilibrium is viewed as the equilibrium point of a tâtonnement process where, at each point of time, districts best react to the last observed actions (Cournot's adjustment process). Clearly, to reach their decisions, districts need not know their rivals' payoff functions and strategy spaces. In a second case, the Nash equilibrium is seen as the equilibrium point of a mental process whereby each district tries to make its best educated guess about the optimal decisions of the other districts. Here on the contrary, the knowledge of others' payoff functions and strategy spaces must be common knowledge. The two following sections consider those two information structures successively and suggest a corrective mechanism for each.

\section{Implementing Matching grants}

In this section, we investigate a simple budget-balanced process that will implement an efficient allocation, while keeping the assumptions regarding the information possessed and used by the districts at a minimal level. Neither the districts nor the benevolent regulator need to know the preferences of the districts all around. In other words, we adopt the first interpretation of the Nash equilibrium discussed in the previous section, as the outcome of an adaptive process.

The federal government is controlling the matching rates and each district $i$ is adjusting optimally its own $z_{i}$ to any change in its own matching rate $s_{i}$ and in the income of its workers $c$. With quasi-linearity of welfare functions, there are no income effects on the first order conditions $\left(d W_{z_{i}}^{i} / d y_{i}=0\right)$.

The process rests on a very simple intuition: observing a Nash equilibrium with an inefficient allocation of labor and an inefficient level of redistribution, efforts need to be made to reduce the dispersion of the transfers while at the same time increasing (decreasing) the level of redistribution. For a desired increase (which holds for sufficiently low matching rates), this is possible by raising the matching rate to the district choosing the lowest transfer. More precisely, let the current equilibrium choices be such that $z_{i}<z_{j}$, all $j$; assuming too little redistribution $\left(\sum_{i}\left(U_{c}^{i}-l_{i}\right)>0\right)$, set $d s_{i}>0, d s_{j}=0 \forall j \neq i$ (the same reasoning applies under reversed signs). This marginal change $d s_{i}$ is announced only to district $i$, that will be induced to adjust unilaterally its own transfer by $d z_{i} \neq 0$ to restore its first-order 
condition. This leads to an effect $d c=\frac{d c}{d z_{i}} d z_{i}$ on $c$ and to migration $d l_{j}=\frac{d l_{j}}{d c}$, $\forall j \neq i$. Then all districts will respond optimally to the resulting change in level of redistribution by $d z_{j} / d c \neq 0$. Each district $j$ will have to pay its share $\varphi_{j}$ of the additional cost of the higher $s_{i}$ and of the changes of $z_{k}$ 's all around. So the process is budget-balanced.

The information required to quantify all those small adjustments can be deduced from the districts' best replies. Let us get back to the first-order conditions (11):

$F_{i}=\left(U_{c}^{i}-l_{i}\right) \sigma_{i}+\left(1-\varphi_{i}\right) s_{i} l_{i}+\left(1-\left(1-\varphi_{i}\right) s_{i}\right)\left(1-\sigma_{i}\right) z_{i} l_{i}^{\prime}-\varphi_{i} \sum_{j \neq i} s_{j} z_{j} \frac{d l_{j}}{d z_{i}}=0$

Differentiating this expression with respect to $z_{i}, l_{i}, c, s_{i}$, while holding $z_{j}, j \neq$ $i$ constant, one has

$$
\left[\frac{\partial F_{i}}{\partial z_{i}}+\frac{\partial F_{i}}{\partial l_{i}} \frac{d l_{i}}{d z_{i}}+\frac{\partial F_{i}}{\partial c} \frac{d c}{d z_{i}}\right] d z_{i}+\frac{\partial F_{i}}{\partial s_{i}} d s_{i}=0
$$

so that

$$
\left.\frac{d z_{i}}{d s_{i}}\right|_{z_{j}}=\frac{-\frac{\partial F_{i}}{\partial s_{i}}}{\left[\frac{\partial F_{i}}{\partial z_{i}}+\frac{\partial F_{i}}{\partial l_{i}} \frac{d l_{i}}{d z_{i}}+\frac{\partial F_{i}}{\partial c} \frac{d c}{d z_{i}}\right]}
$$

where

$$
\begin{aligned}
& \frac{\partial F_{i}}{\partial c}=\sigma_{i} U_{c c}^{i}<0, \\
& \frac{\partial F_{i}}{\partial z_{i}}=\left(1-\left(1-\varphi_{i}\right) s_{i}\right)\left(1-\sigma_{i}\right) l_{i}^{\prime}<0, \\
& \frac{\partial F_{i}}{\partial s_{i}}=\left(1-\varphi_{i}\right)\left(l_{i}-\left(1-\sigma_{i}\right) z_{i} l_{i}^{\prime}\right)>0, \\
& \frac{\partial F_{i}}{\partial l_{i}}=\left(1-\varphi_{i}\right) s_{i}-\sigma_{i} .
\end{aligned}
$$

Therefore

$$
\left.\frac{d z_{i}}{d s_{i}}\right|_{z_{j}}=\frac{\left(1-\varphi_{i}\right)\left(l_{i}-\left(1-\sigma_{i}\right) z_{i} l_{i}^{\prime}\right)}{\sigma_{i}^{2}\left|U_{c c}^{i}\right|+\left|l_{i}^{\prime}\right|\left[\left(1-\left(1-\varphi_{i}\right) s_{i}\right)^{2}-\left(\sigma_{i}-\left(1-\varphi_{i}\right) s_{i}\right)^{2}\right]}>0 .
$$


From the first order condition of each district, one can also quantify the individually optimal adjustment of transfers following an observed change in the common income of the poor:

$$
\begin{array}{cc}
\left.\frac{d z_{i}}{d c}\right|_{z_{j}}= & \frac{-\left[\frac{\partial F_{i}}{\partial c}+\left.\frac{\partial F_{i}}{\partial l_{i}} \frac{d l_{i}}{d c}\right|_{z_{i}}\right]}{\frac{\partial F_{i}}{\partial z_{i}}+\left.\frac{\partial F_{i}}{\partial l_{i}} \frac{d l_{i}}{d z_{i}}\right|_{c}}, \\
= & -\frac{\sigma_{i}\left|U_{c c}^{i}\right|+\left(\left(1-\varphi_{i}\right) s_{i}-\sigma_{i}\right)\left|l_{i}^{\prime}\right|}{\left[1-\left(1-\varphi_{i}\right) s_{i}\left(2-\sigma_{i}\right)\right]\left|l_{i}^{\prime}\right|}, \\
<0 & \text { for } \sigma_{i}<\left(1-\varphi_{i}\right) s_{i}<\frac{1}{2} .
\end{array}
$$

The double inequality at the end of (14) is not unreasonable since $\sigma_{i}<$ $\left(1-\varphi_{i}\right) s_{i}$ holds with many districts and $\left(1-\varphi_{i}\right) s_{i}<\frac{1}{2}$ holds when starting from sufficiently low matching rates. All other districts will respond to the change in $c$. Therefore given the initial $d s_{i}>0$, there obtains $\frac{d z_{i}}{d s_{i}} d s_{i}>0$, $\left.\frac{d c}{d s_{i}}\right|_{z_{j}}=\sigma_{i} \frac{d z_{i}}{d s_{i}} d s_{i}$ and

$$
\begin{aligned}
d c & =\sigma_{i} \frac{d z_{i}}{d s_{i}} d s_{i}+\sum_{j} \sigma_{j} \frac{d z_{j}}{d c} d c, \\
& =\frac{\sigma_{i} \frac{d z_{i}}{d s_{i}} d s_{i}}{1-\sum_{j} \sigma_{j} \frac{d z_{j}}{d c}}>0,
\end{aligned}
$$

with $d z_{j}=\frac{d z_{j}}{d c} d c<0$. To evaluate the welfare effect of this change $d s_{i}$, let $\lambda_{i}=\lambda_{j}$ in (12) for all $i$ and $j$, so that ${ }^{13}$

$$
\Lambda=\sum_{k} U^{k}(c)+\sum_{k} f_{k}\left(l_{k}\right)-c L
$$

Then:

$$
d \Lambda=\sum_{k}\left(U_{c}^{k}-l_{k}\right) d c+\sum_{k}\left(f_{k}^{\prime}\left(l_{k}\right)-c\right) d l_{k}
$$

\footnotetext{
${ }^{13}$ This formulation assumes that desired transfers of resources across districts are implemented otherwise by the federation.
} 
In this expression, the term $\sum_{k} c d l_{k}$ cancels out since $\sum_{k} d l_{k}=0$. So

$$
d \Lambda=\sum_{k}\left(U_{c}^{k}-l_{k}\right) d c+\sum_{k} f_{k}^{\prime} d l_{k}
$$

where

$$
\begin{aligned}
\sum_{k} f_{k}^{\prime} d l_{k} & =\sum_{k \neq i} f_{k}^{\prime} d l_{k}+f_{i}^{\prime} d l_{i}, \\
& =\sum_{k \neq i} f_{k}^{\prime} d l_{k}+f_{i}^{\prime}\left(-\sum_{k \neq i} d l_{k}\right), \\
& =\sum_{k \neq i}\left(f_{k}^{\prime}-f_{i}^{\prime}\right) d l_{k} .
\end{aligned}
$$

For all $k \neq i, d w_{k}=d c-d z_{k}>0$, implying $d l_{k}<0$. Also, because $z_{i}<z_{k} \forall k \neq i$ one can deduce from the equilibrium migration condition that

$$
f_{k}^{\prime}-f_{i}^{\prime}=z_{i}-z_{k}<0
$$

Therefore from (16)

$$
\sum_{k \neq i} f_{k}^{\prime} d l_{k}>0
$$

which together with $\sum_{k}\left(U_{c}^{k}-l_{k}\right) d c>0$, establishes from (15) that $d \Lambda>0$. Thus there has been a progress towards Pareto-efficiency.

Those small reactions stop when each district meets again its first order condition, that is at the new Nash equilibrium corresponding to the new profile of matching rates.

We can repeat the process by selecting again the district with the lowest transfer and raising its matching rate. The previous analysis indicates that this will induce a higher $c$ and a better allocation of labour causing a "total welfare" gain. The process will stop when $z_{i} \simeq z_{j}, \forall i, j$, which is the productive efficiency condition. Total welfare $\Lambda$, being monotonic and bounded, provides a natural Lyapunov function towards verifying that the process will converge, with every limit point yielding production efficiency. We can summarize our result in the following proposition.

Proposition 1. Starting from an equilibrium with too little redistribution and an inefficient allocation of labour, consider the mechanism that, at 
each point in time, increases the matching rate to the district choosing the lowest transfer. When this district and all other districts respond optimally and the inequality in (14) holds, then the total production, the level of redistribution and total welfare are increasing over time. Every limit point of the process yields production efficiency but not necessarily the efficient level of redistribution.

That is: our mechanism achieves an efficient allocation of labour across districts, but not necessarily the efficient level of redistribution. Moreover, there is no guarantee that all districts gain along the process. Therefore we now look for a mechanism which yields a Pareto-efficient level of redistribution and along which all districts gain, thus making the mechanism attractive to every agent. The mechanism is based on voluntary matching grants across agents. In this approach agents set simultaneously their own transfer levels and the rate at which they will match other agents' transfers. In contrast to the above mechanism we assume complete information among agents.

\section{$5 \quad$ Voluntary Matching grants}

To investigate the voluntary provision of matching grants, we start by deriving the willingness-to-pay $\pi_{i j}$ of district $i$ for a marginal adjustment $d s_{j}$ on the matching rate to district $j$. District $i$ understands that: (i) district $j$ will benefit from a higher $s_{j}$ on the transfers $z_{j}$ it pays to its workers and will accordingly be induced to increase its own $z_{j}$; (ii) the other districts $k \neq j$ (including district $i$ ) may do the same and to different extents (under asymmetry); and (iii) district $i$ will have to pay its share of the additional cost of the matching grants resulting from the higher $s_{j}$ and the higher $z_{k}$ 's all around. Then

$$
\begin{aligned}
\frac{d W^{i}}{d s_{j}} & =\frac{\partial W^{i}}{\partial s_{j}}+\sum_{k} \frac{\partial W^{i}}{\partial z_{k}} \frac{d z_{k}}{d s_{j}} \\
& =\left.\frac{\partial y_{i}}{\partial s_{j}}\right|_{z}+\sum_{k}\left(\frac{\partial y_{i}}{\partial z_{k}}+U_{c}^{i} \frac{\partial c}{\partial z_{k}}\right) \frac{d z_{k}}{d s_{j}}
\end{aligned}
$$

where $\left.\frac{\partial y_{i}}{\partial s_{j}}\right|_{z}=\left(\jmath_{i=j}-\varphi_{i}\right) z_{j} l_{j}$ with $\jmath_{i=j}=1$ if $i=j$ and $\jmath_{i=j}=0$ otherwise. Therefore, using $\partial c / \partial z_{k}=\sigma_{k}$ 


$$
\begin{aligned}
\pi_{i j} & =\frac{d W^{i}}{d s_{j}} \\
& =\left(\jmath_{i=j}-\varphi_{i}\right) z_{j} l_{j}+U_{c}^{i} \sum_{k} \sigma_{k} \frac{d z_{k}}{d s_{j}}+\sum_{k} \frac{\partial y_{i}}{\partial z_{k}} \frac{d z_{k}}{d s_{j}} .
\end{aligned}
$$

This expression denotes the willingness of district $i$ to pay for $d s_{j}$ taking into account the impact of $d s_{j}$ on district $i$ 's contribution $\varphi_{i} \sum_{k} s_{k} z_{k} l_{k}$. Adding up (17) over all districts, the aggregate willingness-to-pay for $d s_{j}$ gives

$$
\begin{aligned}
\pi_{j} & =\sum_{i} \pi_{i j} \\
& =\left(\sum_{i} j_{i=j}-\sum_{i} \varphi_{i}\right) z_{j} l_{j}+\sum_{i} \frac{W_{2}^{i}}{W_{1}^{i}} \sum_{k} \sigma_{k} \frac{d z_{k}}{d s_{j}}+\sum_{i} \sum_{k} \frac{\partial y_{i}}{\partial z_{k}} \frac{d z_{k}}{d s_{j}} \\
& =\sum_{i} U_{c}^{i} \sum_{k} \sigma_{k} \frac{d z_{k}}{d s_{j}}+\sum_{i} \underbrace{\frac{\partial y_{i}}{\partial z_{i}} \frac{d z_{i}}{d s_{j}}}_{\text {own effect }}+\sum_{i} \sum_{k \neq i} \underbrace{\frac{\partial y_{i}}{\partial z_{k}} \frac{d z_{k}}{d s_{j}}}_{\text {cross effect }}
\end{aligned}
$$

where the third equality follows from the fact that $\sum_{i} \jmath_{i=j}=\sum_{i} \varphi_{i}=1$.

- The decomposition of the cross effect in (18) yields for $i \neq k$

$$
\begin{aligned}
M_{i k} \equiv & \frac{\partial y_{i}}{\partial z_{k}}=\left.\frac{\partial y^{i}}{\partial z_{k}}\right|_{l}+\left.\frac{\partial y^{i}}{\partial l_{i}}\right|_{z} \frac{d l_{i}}{d z_{k}}+\left.\sum_{h \neq i} \frac{\partial y^{i}}{\partial l_{h}}\right|_{z} \frac{d l_{h}}{d z_{k}} \\
= & -\varphi_{i} s_{k} l_{k}+\left[-f_{i}^{\prime \prime} l_{i}-\left(1-s_{i}\left(1-\varphi_{i}\right)\right) z_{i}\right] \sigma_{k} l_{i}^{\prime} \\
& +\sum_{h \neq i ; h \neq k}\left(-\varphi_{i} s_{h} z_{h}\right) \sigma_{k} l_{h}^{\prime}+\varphi_{i} s_{k} z_{k}\left(1-\sigma_{k}\right) l_{k}^{\prime} \\
= & -\varphi_{i} s_{k} l_{k}-\sigma_{k} l_{i}-\left(1-s_{i}\right) z_{i} l_{i}^{\prime} \sigma_{k}-\varphi_{i} \sigma_{k} \sum_{h} s_{h} z_{h} l_{h}^{\prime}+\varphi_{i} s_{k} z_{k} l_{k}^{\prime}
\end{aligned}
$$

where the second equality follows from (7)-(8) and where we have used the fact that $l_{i}^{\prime}\left(c-z_{i}\right)=f_{i}^{\prime \prime}\left(l_{i}\right)^{-1}$ in the last equation.

- The decomposition of the own effect in (18) yields for $i=k$,

$$
\frac{\partial y_{k}}{\partial z_{k}}=M_{k k}+s_{k} l_{k}+\left(1-s_{k}\right) z_{k} l_{k}^{\prime} .
$$


Therefore combining (19) and (20) yields the aggregate effect,

$$
\begin{aligned}
\sum_{i} \sum_{k} \frac{\partial y_{i}}{\partial z_{k}} \frac{d z_{k}}{d s_{j}}= & \sum_{i} \sum_{k} M_{i k} \frac{d z_{k}}{d s_{j}}+\sum_{k}\left(s_{k} l_{k}+\left(1-s_{k}\right) z_{k} l_{k}^{\prime}\right) \frac{d z_{k}}{d s_{j}} \\
= & -\sum_{k} s_{k}\left(l_{k}-z_{k} l_{k}^{\prime}\right) \frac{d z_{k}}{d s_{j}}-\sum_{i}\left(l_{i}+\left(1-s_{i}\right) z_{i} l_{i}^{\prime}\right) \sum_{k} \sigma_{k} \frac{d z_{k}}{d s_{j}} \\
& -\sum_{h} s_{h} z_{h} l_{h}^{\prime} \sum_{k} \sigma_{k} \frac{d z_{k}}{d s_{j}}+\sum_{k}\left(s_{k} l_{k}+\left(1-s_{k}\right) z_{k} l_{k}^{\prime}\right) \frac{d z_{k}}{d s_{j}} \\
= & -\sum_{i} l_{i} \sum_{k} \sigma_{k} \frac{d z_{k}}{d s_{j}}+\sum_{k} z_{k} l_{k}^{\prime}\left(\frac{d z_{k}}{d s_{j}}-\sum_{h} \sigma_{h} \frac{d z_{h}}{d s_{j}}\right)
\end{aligned}
$$

Substituting (21) into (18) yields

$$
\pi_{j}=\sum_{i}\left(\frac{W_{2}^{i}}{W_{1}^{i}}-l_{i}\right) \sum_{k} \sigma_{k} \frac{d z_{k}}{d s_{j}}+\sum_{k} z_{k} l_{k}^{\prime}\left[\frac{d z_{k}}{d s_{j}}-\sum_{h} \sigma_{h} \frac{d z_{h}}{d s_{j}}\right] .
$$

The second term in (22) is the covariance across districts between $z_{k} l_{k}^{\prime}$ and $d z_{k} / d s_{j}$. Using $\sigma_{k}=l_{k}^{\prime} / \sum_{h} l_{h}^{\prime}$, this covariance can be written as

$$
\begin{aligned}
\operatorname{cov}\left(z l^{\prime}, \frac{d z}{d s_{j}}\right) & \equiv \sum_{k} z_{k} l_{k}^{\prime}\left[\frac{d z_{k}}{d s_{j}}-\sum_{h} \sigma_{h} \frac{d z_{h}}{d s_{j}}\right], \\
& =\sum_{k} z_{k}\left[\sigma_{k} \frac{d z_{k}}{d s_{j}}-\sigma_{k} \sum_{h} \sigma_{h} \frac{d z_{h}}{d s_{j}}\right] \sum_{h} l_{h}^{\prime}, \\
& =\sum_{k} z_{k}\left[\Delta_{k j}\right] \sum_{h} l_{h}^{\prime},
\end{aligned}
$$

where $\sum_{k} \Delta_{k j}=0$ for all $j$. Letting $\bar{z}=\sum_{h} \sigma_{h} z_{h}$ and rearranging we have

$$
\begin{aligned}
\operatorname{cov}\left(z l^{\prime}, \frac{d z}{d s_{j}}\right) & =\sum_{h} l_{h}^{\prime} \sum_{k}\left(z_{k}-\bar{z}\right) \sigma_{k}\left[\frac{d z_{k}}{d s_{j}}-\sum_{h} \sigma_{h} \frac{d z_{h}}{d s_{j}}\right] \\
& =\sum_{h} l_{h}^{\prime} \sum_{k}\left(z_{k}-\bar{z}\right) \sigma_{k} \frac{d z_{k}}{d s_{j}}
\end{aligned}
$$

where the second equality follows from $\sum_{k}\left(z_{k}-\bar{z}\right) \sigma_{k}=0$. Substituting (23) into (22) and using again $\sigma_{k}=l_{k}^{\prime} / \sum_{h} l_{h}^{\prime}$, 


$$
\pi_{j}=\underbrace{\sum_{i}\left(U_{c}^{i}-l_{i}\right) \sum_{k} \sigma_{k} \frac{d z_{k}}{d s_{j}}}_{\text {redistribution efficiency }}+\underbrace{\left(\bar{z}-z_{j}\right)\left|l_{j}^{\prime}\right| \frac{d z_{j}}{d s_{j}}+\sum_{k \neq j}\left(\bar{z}-z_{k}\right)\left|l_{k}^{\prime}\right| \frac{d z_{k}}{d s_{j}}}_{\text {production efficiency }} .
$$

Therefore, the total willingness to pay (net of the cost) for the matching rate $d s_{j}$ corresponds to the two efficiency considerations. The redistribution efficiency term is positive if a higher matching rate to district $j$ can bring the level of redistribution closer to its optimal level. Indeed since $\sum_{k} \sigma_{k} \frac{d z_{k}}{d s_{j}}=d c / d s_{j}$, this term is positive in the case of under-redistribution when $d c / d s_{j}>0$ and in the case of over-redistribution when $d c / d s_{j}<0$. The productive efficiency term is positive if subsidizing more district $j$ can induce a more efficient allocation of labour. The first component is the ownproductivity effect of $s_{j}$ and the second one is the cross-productivity effect of $s_{j}$. The own productivity effect is positive if $\left(\bar{z}-z_{j}\right) \frac{d z_{j}}{d s_{j}}>0$ so that a higher $s_{j}$ induces district $j$ to set $z_{j}$ closer to the mean, implying less distortion in the allocation of labour. In addition, a higher $s_{j}$ also induces a change in the choice of $z_{k}$ by all other districts $k \neq j$, with an overall reduction of the distortion in the allocation of labour if on average it reduces the spread of $z_{k}$ so that $\sum_{k \neq j}\left(\bar{z}-z_{k}\right)\left|l_{k}^{\prime}\right| \frac{d z_{k}}{d s_{j}}>0$.

It is worth noting that total willingness to pay is the sum of two terms, reflecting respectively redistribution and production efficiency conditions, each of which is necessary for Pareto efficiency. Equating the sum to zero does not imply that each term is equal to zero. Thus total willingness to pay may be equal to zero even though a pareto optimal allocation is not reached. To sum up,

Proposition 2: (a) Under productive efficiency (i.e., $z_{k}=\bar{z} \forall k$ ) and $\sum_{k} \sigma_{k} \frac{d z_{k}}{d s_{j}}>0$, the aggregate willingness-to-pay for $d s_{j}$ is positive if and only if there is an inefficiently low level of redistribution. (b) Under an efficient level of redistribution, the aggregate willingness-to-pay for $d s_{j}$ is positive if it produces a more efficient allocation of labour (i.e., reallocating labour from over-employment district $k$ where $z_{k}>\bar{z}$ to under-employment district $h$ where $\left.z_{h}<\bar{z}\right)$.

This proposition suggests the possibility of reaching the efficient level of redistribution and the efficient allocation of labour through some adjustment 
process based upon voluntary contributions. In Section 6 we will explore an extension of the so-called MDP adjustment process for pure public goods. ${ }^{14}$

\section{Adjustment process}

To achieve productive efficiency, matching rates $s_{j}$ must be differentiated to induce districts to choose uniform transfer level. To insure that every district gains, one must introduce $k$ possibly different cost shares $\varphi_{j}$ in the funding of the programme. So there are altogether $2 k$ decision variables to be selected so as to satisfy three conditions:

(i) productive efficiency: calling for identical wages and transfers across districts;

(ii) efficient level of redistribution as required by the Bowen-LindahlSamuelson condition;

(iii) individual rationality: such that every district benefits from the programme.

In principle there are enough decision variables to satisfy the three conditions simultaneously through some adjustment process based on voluntary contributions. We define a natural adjustment process for the matching rates and the cost shares that will lead agents to the efficient outcome.

Suppose at each point in time districts announce their marginal willingness to pay for matching rates. The process begins at time $t=0$ (with $s_{j}(0)=0 \forall j$ ) and revises the matching rates and net incomes of each district according to the following system of differential equations: ${ }^{15}$

$$
\left\{\begin{array}{cc}
\dot{s_{j}}=\pi_{j}=\sum_{i} \pi_{i j}, & \text { for all } j \\
\dot{y}_{i}=-\sum_{j} \pi_{i j} \dot{s_{j}}+\delta_{i}\left[\sum_{j} \pi_{j} \dot{s_{j}}\right] & \text { for all } i .
\end{array}\right.
$$

That is, at each point in time: (i) the matching rate to each district $j$ is adjusted by an amount equal to the aggregate willingness to pay for this adjusment; and (ii) each district $i$ pays for this adjustment in matching rates an amount equal to its own willingness to pay and receives a share $\delta_{i}$ $>0$ (with $\sum_{i} \delta_{i}=1$ ) of the total surplus resulting from the adjustment in matching rates, $\sum_{j} \pi_{j} \dot{s}_{j}=\sum_{j} \pi_{j}^{2} \geq 0$.

\footnotetext{
${ }^{14}$ This procedure has been proposed independently by Malinvaud (1972) and Drèze and De la Vallee Poussin (1971).

${ }^{15}$ The adjustments in net incomes $\dot{y}_{i}$ can be obtained through adjustments in the cost shares.
} 
Under truthful revelation of the $\pi_{i j}$ 's, this procedure has several desirable properties. First, it is making every district better off at each point in time. ${ }^{16}$ Indeed letting $V^{i}\left(y_{i}, \mathbf{s}\right)$ denote the (quasi-linear indirect) utility function of each district $i$ as a function of its net income and of the matching rates,

$$
\begin{aligned}
\frac{d V^{i}}{d t}\left(y^{i}, \mathbf{s}\right) & =\dot{y}_{i}+\sum_{j} \pi_{i j} \dot{s_{j}} \\
& =\delta_{i} \sum_{j} \pi_{j} \dot{s_{j}} \\
& =\delta_{i} \sum_{j} \pi_{j}^{2} \geq 0 \quad \text { for } \delta_{i}>0 .
\end{aligned}
$$

Second, every limit point of the process is a Pareto optimum, since then $\dot{s}_{j}=\pi_{j}=0$ for all $j$. The monotonicity of the utilities implies the (weak) convergence of the process; taking the sum of utilities as a Lyapunov function,

$$
L(t)=\sum_{i} V^{i}(t)
$$

which is monotonically increasing, with derivative equal to zero only at a stationary point. The strict concavity of $V^{i}$ implies the global convergence of the process to a unique stationary point. Therefore we have proven the following result.

Proposition 3. Under complete information of the districts and truthful revelation, consider the process that, at each point in time, increases the matching rate to each district by an amount equal to the aggregate willingness to pay for the marginal adjustment of this matching rate and adjusts the cost shares so that each district pays for this adjustment in matching rates an amount equal to its own willingness to pay while receiving a share of the total surplus produced. This process is making every district better off at each point in time. The process converges to a stationary solution which is a Pareto optimum if transfers are equalized.

\footnotetext{
${ }^{16}$ The restriction to a quasi-linear objective function is needed to prevent the (Nash) equilibrium choice of $z_{i}$ to be affected by the redistribution of the surplus resulting from the adjustment process. With quasi-linearity we have $\partial z_{i} / \partial y^{i}=0$ which implies nondistortionary redistribution of the surplus.
} 
The last part of the proposition refers to the fact that the total marginal willingess to pay is the sum of two terms reflecting respectively the redistribution and production efficiency conditions. Total willingess to pay equal to zero is a necessary but not sufficient condition for achieving both production and redistribution efficiciency. However if we observe equal transfers at the stationary solution, then production efficiency is attained and thus necessarily redistribution efficiency and Pareto efficiency are also attained.

Proposition 3 still leaves open a crucial question however. Why should the regions submit their true willingness to pay? Why should they reveal their preferences and technologies? Does it pay sometimes to misrepresent those pieces of information? The answer is that it could. Indeed each district could gain from misrepresenting its willingness to pay so as to manipulate the adjustment process to his own advantage (e.g. by claiming low tastes for redistribution to receive higher matching grants). This issue has been addressed in the literature for a pure public good problem where agents are asked to announce their willingness to pay and the regulatory authority provides directly the public good. For instance, Drèze and De la Vallee Poussin (1971) have shown that truthful revelation at each point in time is a maximin strategy (i.e., the best response to the most unfavorable strategies of the other players). The main result here is that truthful revelation is a dominant strategy at a stationary point (see Drèze and De la Vallée Poussin, 1971). But in general revelation in dominant strategy is problematic (See Laffont, 1988, chapter 5). Nevertheless, even if participants misrepresent their preference, Roberts (1979) has shown that the MDP process still generates Pareto optimal outcomes: the effect of preference manipulation is simply to slow down the adjustment process and to select a different Pareto optimum.

\section{Conclusion}

The European enlargement is the largest single expansion that the European Union has ever experienced, with ten countries and 73 million people joining the club. It is not just the largest EU expansion, but also the most diversifying; the gap in the living standards between existing EU nations and those that are joining is far wider than in previous enlargements. One of the great benefits of EU membership for citizens from the new countries is the right to live and work in the rest of the EU. Although East European economies have been growing rapidly in the past ten years, average wages are still only 
12 percent of those of Britain. Granting immediate employment and full access to the welfare state could produce ample migration. Some economists have argued that open-border immigration policy is incompatible with a welfare state and will trigger a race to the bottom. Other pro-immigration economists argue that it will attract workers who are needed in key sectors and so will not be a burden on the public budget. For employers, mobility enables recruitment from a wider pool of workers and helps to alleviate regional skills shortages. It will attract skills and boost the economy.

In this context, we have examined a fiscal competition game in which the contribution by one state to support the income of its workers may affect other states through the induced migration. Due to this migration externality the Nash equilibrium is typically inefficient: there is too little redistribution to low-skilled workers due to the fear of immigration; and different districts will choose different redistributive policies so that wages are not equalized resulting in inefficient allocation of labour across the federation. To achieve the efficient allocation, each district must face the correct "price" for its choice. Wildasin (1991) proposes a solution involving differentiated matching grants. He shows that there exist levels of these matching grants inducing an efficient Nash equilibrium in spite of district differences in production possibilities and preferences for redistribution. The problem is how to determine the correct matching rates so that all districts would benefit: the regulator may not have access to the information (about technology and preferences) needed to implement an efficient outcome.

Our purpose has been to design a decentralized process that will implement an efficient allocation, when each district possesses the relevant information about preferences and technology in the other districts. In addition to implementing efficient outcomes, the process should be acceptable to every agent. Our process is based on voluntary matching grants by the districts themselves. This is a process where districts choose their own transfers and announce the rates at which they will match the transfers in other districts. We have examined some adjustment process capable of producing an efficient solution. Under this process the matching rates are progressively adjusted based on what agents are willing to pay and costs are shared so that every district gains. We have also proposed a simpler mechanism more parsimonious in information in which the central authority increases matching rate of the district choosing the lowest transfer and all the districts simply adjust their own transfer to the new level of redistribution. We have shown that this process increases total production and the level of redistribution so that total welfare is increasing over time. However, in contrast to the above mechanism, all districts may not gain, and the process may stop 
before attaining the efficient level of redistribution.

One final question concerns the complexity of the mechanisms we have proposed. Would districts really understand the nature of the process in which they participate? Recent work by Clement et al (2007) tries to assess the performance of the dynamic MDP process in the laboratory. Admittedly it has been harder to explain to subjects than other static mechanisms. Still, they managed to understand their decision context after some time; their understanding has been checked via a questionnaire before the beginning of the experiment, and nothing during the experiment did cast doubts about their ability to grasp the problem. Of course laboratory experiment is not the real world of the European Union. And we must accept that it is hard to believe that member states will ever accept to provide Federal grants primarily to those states redistributing less than others. However our analysis still suggests the possibility of achieving welfare improvement with uniform grants. This is a simpler approach that we did not pursue and which clearly deserves further investigation.

\section{References}

[1] Bean, C., S. Bentolila, G. Bertola and J. Dolado, 1998, Social Europe: One for all? London:CEPR.

[2] Belot M. and J.P. Ederveen (2006) Cultural and Institutional Barriers to Migration Between OECD Countries, Discussion paper CPB Netherlands Bureau for Economic Policy Analysis, The Hague, forthcoming.

[3] Bertola, G., T. Boeri and G. Nicoletti (2001), Welfare and Employment in a United Europe, MIT Press, Cambridge.

[4] Blackorby, C., W. Bossert and D. Donaldson, 2005, Population Issues in Social Choice Theory, Welfare Economics, and Ethics, Cambridge University Press, Cambridge.

[5] Brown, C. and W. Oates, 1987, Assistance to the poor in a federal system, Journal of Public Economics 32(3), 307-330.

[6] Brueckner, J.K., 2000, Welfare Reform and the Race to the Bottom: Theory and Evidence, Southern Economic Journal 66(3), 505-525.

[7] Clément, V., C. Figuières, J. Vyrastekova and M. Willinger, 2007, An experimental investigation of the MDP process, mimeo. 
[8] Crépon, B. and R. Deplatz, 2002, Une nouvelle évaluation des effets des allègements de charges sociales sur les bas salaires, Economie et Statistiques 348.

[9] Costello, D., 1993, Intergovernmental grants: what role for the European Community?, European Economy, no 5.

[10] Drèze, J.H., and D. De la Vallee Poussin, 1971, A tâtonnement process for public goods, Review of Economic Studies, 38, 133-50.

[11] Drèze, J.H., and J. Greenberg, 1980, Hedonic coalitions: optimality and stability, Econometrica 48, 4, 987-1003.

[12] Drèze, J.H., 2000, Economic and Social Security in the Twenty-first Century, with Attention to Europe, Scandinavian Journal of Economics, 102, 327-48.

[13] Drèze, J.H., 2002, Economic and social security: the role of the EU, De Economist 150, 1-18.

[14] Figuières, C. and J. Hindriks, 2002, Matching grants and ricardian equivalence, Journal of Urban Economics,52, 177-91

[15] Figuières, C., J. Hindriks and G. Myles, 2004, Revenue sharing vs expenditure sharing in a federal system, International Tax and Public Finance 11, 155-74.

[16] Guttman, J. 1978, Understanding collective action: matching behavior, American Economic Review (Papers and Proceedings), 68, 251-55.

[17] Hindriks, J., 1999, The consequences of labour mobility for redistribution:tax versus transfer competition, Journal of Public Economics 74, 215-34.

[18] Hindriks, J., and G.D. Myles, 2003, Strategic inter-regional transfers, Journal of Public Economic Theory 5, 229-48.

[19] Laffont, J.-J, 1988, Fondements de l'Economie Publique, (Coll. Economie et Statistiques avancées), Economica.

[20] Lodemel, I. and Trickey H., 2000, A new contract for social assistance, in: Lodemel, I. and Trickey H. (Eds), 'An offer you can't refuse', Workfare in international perspective. Bristol: Policy Press, 1-40. 
[21] Malinvaud, E., 1972, Prices for individual consumption, quantity indicators for collective consumption, Review of Economic Studies, 39, 385-405.

[22] Oates, W.E., 1972, Fiscal federalism, Harcourt Brace Jovanovich: New York.

[23] Pfingsten A. and A. Wagener, 1997, Centralized vs. Decentralized Redistribution: A case for Interregional Transfer Mechanisms, International Tax and Public Finance 4, 429-451.

[24] Roberts, J., 1979, Incentives in planning procedures for the provision of public goods, Review of Economic Studies, 46, 283-92.

[25] Roberts, K., 1999, Dynamic voting in clubs, LSE discussion paper No. $\mathrm{TE} / 99 / 367$.

[26] Sinn, H.-V., 1990, Tax harmonization and tax competition in Europe, European Economic Review 34, 489-504.

[27] Sinn, H.-V., 2003, The New Systems Competition, Yrjö Jahnsson Lectures, Blackwell Publishing: Oxford.

[28] Varian, H.R., 1994, A solution to the problem of externalities when agents are well-informed, American Economic Review 84, 1278-93.

[29] Wildasin, D.E., 1991, Income redistribution in a common labor market, American Economic Review 81, 757-74.

[30] Wildasin, D.E., 1988, Nash equilibria in models of fiscal competition, Journal of Public Economics 35, 229-240.

[31] Wildasin, D.E., 2000, Factor mobility and fiscal policy in the EU: policy issues and analytical approaches, Economic Policy, October, 339-78.

[32] Wilson, J.D., 2006, Protecting the welfare state from international migration, mimeo, Michigan State University. 